\title{
Chaos Narrative and Experientiality in the Graphic Memoir
}

\section{The Case of Thomas H. Nøhr's Cirkus}

\section{Lasse Raaby Gammelgaard}

School of Communication and Culture (CC), Aarhus University (AU) norlg@cc.au.dk

Gammelgaard, Lasse Raaby. (2019) Chaos Narrative and Experientiality in the Graphic Memoir: The Case of Thomas H. Nøhr's Cirkus . Tidsskrift for Forskning i Sygdom og Samfund, nr. 31, 89-105.

This article contributes to research on illness narratives. It revisits Arthur Frank's notion of the chaos narrative and argues in favour of supplementing it with the concept of tellability, and with Monika Fludernik and David Herman's postclassical narratological approaches to the definition of narrative that foreground experientiality and what it's like. Furthermore, it is argued that tellability is recuperated at the discourse level in literary representations of the chaos narrative. Frank argues, that the chaos narrative cannot be represented, but in this article, the case is made that literature can mimick the chaos. It is suggested, to label this particular chaos narrative: The mediated chaos narrative. This is demonstrated in a reading of Danish cartoonist Thomas H. Nøhr's graphic memoir entitled Cirkus, which chronicles his encounter with the Danish health care system after suffering from stress, depression and severe burnout. The graphic memoir can experiment with the affordances of its multimodality to support the focus on narrative experientiality and to draw attention to issues of social justice. To render the chaos of the experience, Nøhr examines how the affordances of graphic memoir enables one to experiment with narratological 
building blocks such as the distinction between the narrating I and the experiencing I and with Gérard Genette's three categories of time: order, duration, and frequency.

Illnesses pose a challenge for the construction of a narrative. Since Aristotle's Poetics, plot - understood as a sequence of events or actions with a teleologically and causally based thread from the beginning through the middle to the end - has been crucial to attempts at defining a narrative. It can be difficult, though, to understand one's life as a plot-driven narrative, when it is interrupted by illness. To account for different illness narratives, the sociologist Arthur Frank introduces three types of illness narratives in his seminal book The Wounded Storyteller: the restitution narrative, the quest narrative, and the chaos narrative. The first subsection of the chapter on the chaos narrative is entitled "Chaos as Non-Plot" (Frank, 1995, 97).

In this article, I will revisit Frank's chaos narrative and couple it with alternative definitions of narrative from postclassical narratology, where the emphasis is less on plot and more on experientiality (in Monika Fludernik's terms) and what-it's-like (in David Herman's terms). Furthermore, I want to argue, that the particular genre of the graphic memoir (i.e. comics autobiography) is primed to meet the challenge chaos narratives pose to the very category of narrative. My empirical case for probing these issues will be Cirkus by Thomas H. Nøhr. ${ }^{1}$ Cirkus is a graphic memoir about mental illness and about the Danish health care system. I will commence by introducing Nøhr's work. This enables me to interpret my empirical case as I broach and discuss the relevant theory. Cirkus depicts a chaos narrative and in doing so, the protagonist's experientiality is foregrounded. I will argue, that his alternative experience of time necessitates an experimental rendition of time experience. The affordances of the graphic memoir are well suited to represent and experiment with narratological categories of time and narrative situations.

\section{Social Justice and Nøhr's Artistic Accounts of the Danish Health Care System}

Cartoon artist Thomas H. Nøhr has written a number of cartoons - ranging from comic strips to (short) graphic memoirs - based on his personal experience with stress and his confrontation with the Danish welfare system. They were first pub- 
lished online, but they have since been published collectively in Når jeg tegner... (translation: When I Draw...) in 2017. In a comic strip, Fun with my Brain, which has six panels, an unseen interlocutor asks him how he is feeling. Nøhr never replies, but his reflections are captured in thought bubbles. He has pain in his stomach and back, he feels stress all the time, he has headaches and is concerned about his bad memory and he feels safe but isolated in his home. In the final panel, he reflects: "I worry about politics and social injustice, but maybe I'm just hypersensitive?" (Nøhr, 2007: 27). ${ }^{2}$ The issue of social justice is often evident even at a titular level. One, for instance, is subtitled "Fun and Games with the Rather Large Mesh Social Safety Net" (37), while another subtitle goes "An Allegorical Catharsis Journey Through the Mind of the Author + A Rollercoaster Ride Through the Public Sector Represented in Bright Colors" (59).

Nøhr's autobiographical comics Cirkus (Circus), Hu hej, tiden flyver (Time Flies), and Livets skyggeside (Outcast of Fortune) were composed as "the result of an acute necessity like a sudden nausea that could not be suppressed" (quoted in Larsen 2015). They describe Nøhr's experience of severe stress, a condition that was allowed to exacerbate for way too long before he sought out help. In an interview in 2015, Nøhr explains, that his therapist is still trying to decipher the nature of his mental condition, but that he has stress, depression and severe burnout. He says that his state resembles post-traumatic stress disorder. On the one hand, Nøhr uses his comics to find a language that accurately depicts his mental state but they also chronicle and subjectively criticize the Danish welfare system. Nøhr explains, that when he finally asked the system for help, "an entire year went by, before I was told that nothing had happened with my case, that I had been forgotten" (quoted in Larsen 2015). The delays went on and on, and at one point he started composing the aforementioned graphic memoirs. Nøhr finally received disability pension in 2015. The interview I have quoted from was done a few months after that, and in it Nøhr describes his hopes (or lack thereof) for the future:

"I have given up all ambitions about ever doing anything again. I'm completely exhausted. I don't know if I'll ever get well again, and my shrink tells me that there are no guarantees that this mental burnout will get better. And since I'm numbed, I strangely enough can't feel whether this is a good or bad thing." (quoted in Larsen 2015)

Nøhr was interviewed again in 2017 after Når jeg tegner... was published. Here, he describes his condition and future again: 
"Now I feel like a normal human being again. But I have no plans to return to drawing. My aim now is to do as little as possible, except for trying to lose the 70 kilos I gained during my ten years with stress and depression" (quoted in Andreasen).

In this article, I am going to focus on Cirkus. Cirkus is a rather short graphic memoir, consisting of only 15 pages (front cover included). The story itself - or, if you will, the "plot" - is even shorter; it is told in the first six pages, and then it is subsequently repeated throughout the remaining pages of the memoir. I will summarize it in some detail, because it is rather brief and because doing so is relevant to my interpretation.

In the first panel, the protagonist visits a health care office and says: "Hello - I'm broken - is this where I can get help?" The front desk secretary replies: "Absolutely." He is told that he needs to go see his doctor in order to get a referral to a psychiatrist and that he subsequently must procure statements from both the doctor and the psychiatrist about his condition. The doctor swiftly concludes that he is not looking well and that he will give him the referral. At this point, the bureaucracy kicks in; he is told that the wait to get an appointment with a psychiatrist is six months. He waits six months, while his condition exacerbates. He then sees the psychiatrist once a month for six months, after which the psychiatrist concludes that: "It is now abundantly clear - you need to receive a disability pension" (which essentially puts you on social benefits for life). He eventually returns to the health care office, providing the secretary with the statements from the psychiatrist and the doctor. He is told to take a seat in the waiting room (this is quoted in figure 1). After an unspecified amount of time (it takes more than 4 months...), he goes back to the health care office, and at this point he is only able to utter one syllable: "Help..." The secretary, smiling friendly as ever, tells him that he has been assigned to a new caseworker and that the statements from the doctor and the psychiatrist are now out of date; he will need to get new ones.

It turns out to be the end of the plot because this brief sequence then repeats itself - to infinity, it is suggested. However, as the story repeats itself, numerous changes to the representation of the same events are made at the discourse level. In figure 2, you see the third and fourth time the events that I just detailed are repeated. In figure 3 - which quotes the pages right after figure 2 - we can no longer count how many times the protagonist has procured statements and had them rejected: 

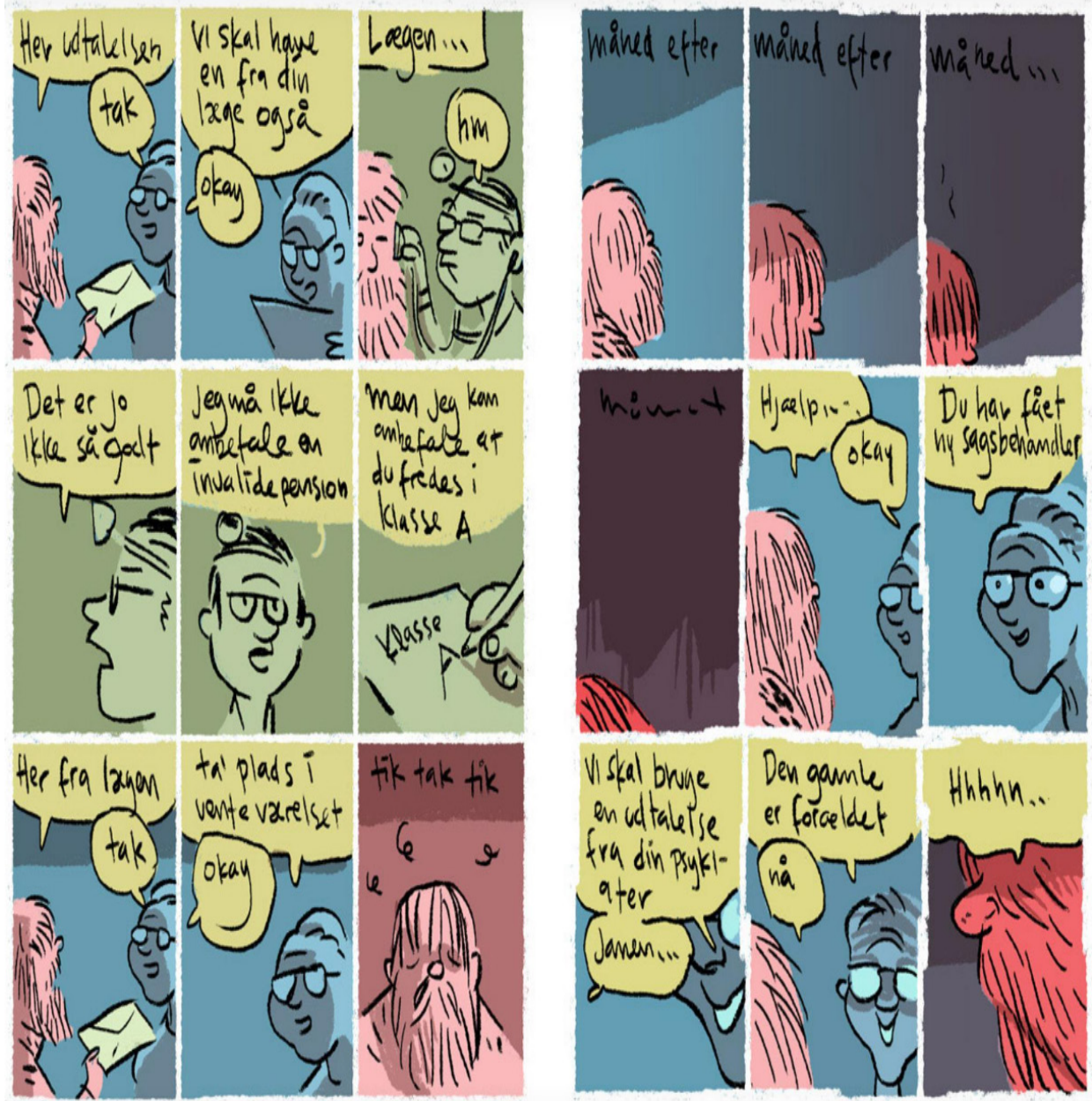

Figure 1: "Cirkus" in Når jeg tegner..., pp. 104-105. 


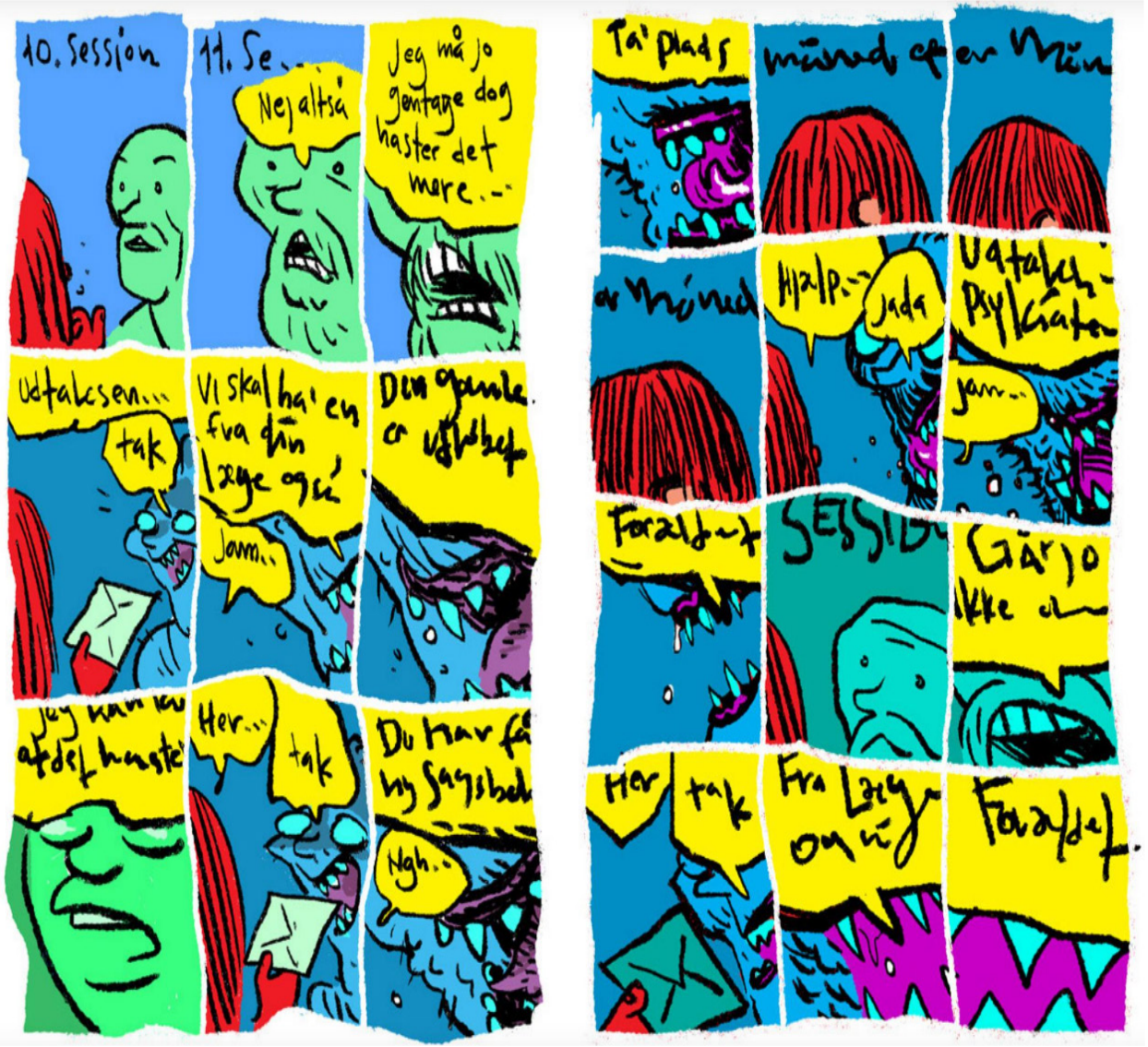

Figure 2: "Cirkus" in Når jeg tegner..., pp. 108-109. 


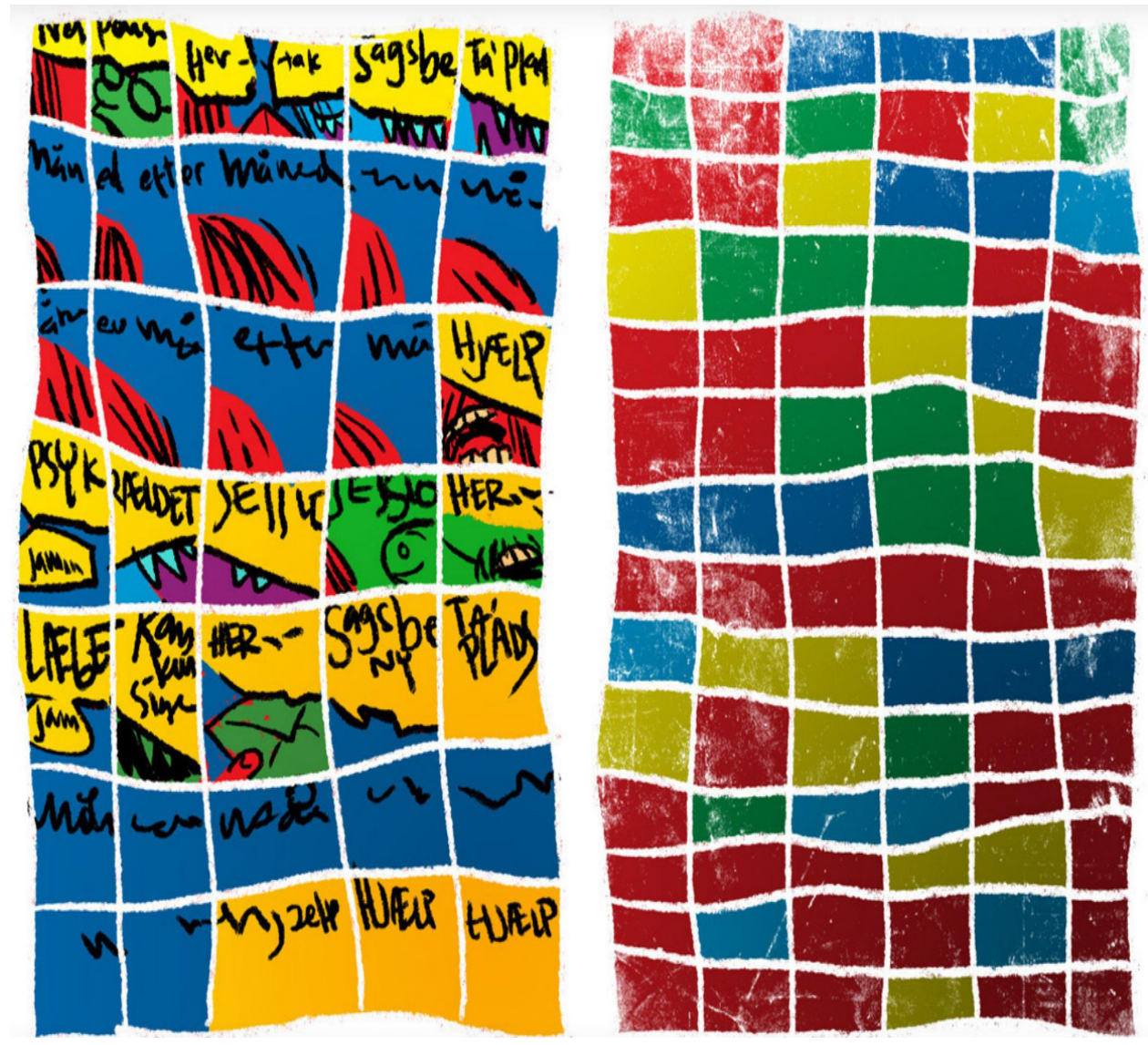

Figure 3: "Cirkus" in Når jeg tegner..., pp. 110-111.

\section{Narrative and Illness: Losing the Plot}

Illness is never planned for. Rather, it is part of life's contingency. As Schlomith Rimmon-Kenan has argued, "[a]utobiographical writing about illness may be an attempt to control the uncontrollable, and hence it can become a battleground between the two competing principles [i.e. of the dictated order that hospitalization effects, and the inner disorder the patient feels]" (Rimmon-Kenan, 2006: 244). Frank's first two types of illness narratives are exactly such attempts at mastery. Restitution narratives are about the restoration of health or the triumph of medicine. Frank paraphrases its storyline as follows: "Yesterday I was healthy, today I'm sick, but tomorrow I'll be healthy again"' (Frank, 1995: 77). In quest narratives, patients "meet suffering head- 
on; they accept illness and seek to use it. Illness is the occasion of a journey that becomes a quest," and the ill person believes "that something is to be gained through the experience" (Frank, 1995: 115). Chaos narratives are completely distinct from restitution and quest narratives. Frank states that:

"Chaos is the opposite of restitution: its plot imagines life never getting better. Stories are chaotic in their absence of narrative order. Events are told as the storyteller experiences life: without sequence or discernable causality." (Frank, 1995:

97)

Hence, to Frank, chaos narratives might not even be narratives. Furthermore, chaos narratives are characterized by "the syntactic structure of 'and then and then and then,"' which results in a "staccato pacing of words [that] pecks away at the reader" (Frank, 1995: 99). In my summary of Cirkus, I deliberately tried to render the syntax of 'and then and then and then.' As a consequence "chaos stories are hard to hear" (Frank, 1995: 97). I find it profitable to supplement Frank's theory of chaos narrative with the concept of tellability to account for its unlistenable trait. Tellability is "a quality that makes stories inherently worth telling, independently of their textualisation" (Ryan, 2005: 589). The concept originates in oral storytelling, but it is often regarded as a criterion for narrativity.

When tellability is expanded to describe complex constructions in literary genres, it is necessary to invoke the narratological distinction between story and discourse. Story relates to what is told (independently of style and formal choices), whereas discourse designates how something is told. Tellability can be employed either as a concept that is independent of or characterized by the discourse level. Baroni writes that "narrative interest might be proposed as a term for tellability when dealing with the interconnection between story and discourse" (Baroni, 2011). It is precisely my argument that Cirkus has very low degrees of tellability at the story level, where the same non-event continually repeats itself, but that tellability is nonetheless recuperated at the discourse level. Any medium has a unique set of possibilities and limitations. Non-moving images, for instance, represent space in a frozen moment of time; movies show moving images; comics present sequences of non-moving images. Such possibilities and limitations constitute media affordances. Images, movies and comics obviously have many other affordances than the ones I just mentioned. Readers, I argue, take pleasure in engaging with Nøhr's experimentation with the affordances of the multimodality of the graphic memoir. 
This, in turn, renders Nøhr's experience relevant, even as the story or plot is not in itself particularly tellable.

At this point, I would raise a critique of Frank's implicit definition of narrative as being too reliant on plot with its combination of telos and causality. In alternative definitions of narrative, plot structure is only one of the defining features. I want to single out two of these, which are related; namely, Fludernik's concept of experientiality and Herman's prototypical approach. Fludernik writes, that a personal narrative is a narrative "not because it tells a story, but because the story that it tells is reportable," and, consequently, "tellability and point of the story dialectically constitute each other" (Fludernik, 1996: 70). In general, however, what endows something with the quality of narrativity is what she terms experientiality. Experientiality is defined as "the quasi-mimetic evocation of 'real-life experience"' (Fludernik, 1996: 12). Fludernik argues, that all narratives rely on the activation of cognitive frames and schemata that humans rely on in their actual lives. Experientiality, in Fludernik's argument, is much more essential to narrativity than plot:

"In my model there can, therefore, be narratives without plot, but there cannot be any narratives without a human (anthropomorphic) experiencer of some sort at some narrative level." (Fludernik, 1996: 13)

Fludernik even goes to the extreme of claiming that "[m]erely plot-oriented narratives are [...] argued to represent a zero degree of narrativity even though they are traditionally endowed with proto-typical narrativity" (Fludernik, 1996: 13). While I recognize the fecundity in foregrounding human-like experience as a previously neglected and essential element in all narratives, I do not find the bold claim about plot to be productive. In defining what makes something a narrative, I would lean more towards David Herman's prototypical approach. According to Herman, prototypical narratives are constituted through four basic elements (Herman, 2009: 9): situatedness (the idea that a representation is situated in a specific discourse context or occasion for telling), event sequencing (the notion that interpreters draw inferences about a structured time-course of particularized events), worldmaking/world disruption (the events introduce a disruption or disequilibrium into a storyworld), and, finally, what it's like (i.e. the representation conveys the experience of living through the events represented; this is related to Fludernik's experientiality). In introducing four basic elements of narrative, Herman suggests that "capturing what it's like to experience storyworld events constitutes a critical property of but not a sufficient condition for narrative" (Herman, 2009: 139). A narrative that is constituted by all 
four basic elements - situatedness, event sequencing, worldmaking/world disruption, and what it's like - is a prototypical narrative, while narratives which only contain some of these are less prototypical; they have lower degrees of narrativity.

"What it's like," which Herman also calls the consciousness factor, is comparable to Fludernik's experientiality. In Herman's words, this element describes the fact that.

"[n]arrative representations convey the experience of living through storyworldsin-flux, highlighting the pressure of events on real or imagined consciousnesses affected by the occurrences at issue." (Herman, 2009: 137; his emphasis).

Because of the somewhat arbitrary nature of life and illness and because experiencing illness can feel chaotic some illness narratives are difficult to represent. The raw story of Nøhr's Cirkus would appear to be almost impossible to make tellable. It was created and posted online when Nøhr was caught up in the bureaucracy, which delayed the arrival of the help he needed. It is not at all hopeful that health will be restored or that something is to be gained from the experience, so it is far removed from restitution and quest narratives. Rather, it suggests that waiting for the health care system to deliver help is like waiting for Godot in Samuel Beckett's absurdist theatre. The lack of narrative progression - marked by the 'and then and then and then' nature of the unfolding of the story - results in endless repetitions. Hence, Cirkus fits Frank's notion of the chaos narrative, but I would not call it an anti-narrative. It certainly is not a prototypical narrative, but it does fulfil certain criteria of narrativity. If we relate it to Herman's basic elements, it does have situatedness, as Nøhr posted it on Facebook, an occasion that was necessitated by his nausea. However, I would argue, that its relation to the element of event sequencing is volatile at best. Nøhr is trying to take action but everything is static at the story level. The element of worldmaking/world disruption is not introduced in prototypical fashion either. It seems like the stable storyworld (i.e. Nøhr's life) exists prior to the opening of this story. The disequilibrium or rupture then takes place in the very first panel, when he asks a professional for help. From then on, we just go round in circles. What it is like or experientiality, however, is foregrounded. This is a story about Nøhr's subjective experience of the disintegration of his mental health as the bureaucracy of the welfare state's health sector puts him under even more stress. Hence, Cirkus highlights experientiality in a way that draws attention to the drawbacks of the psychiatric system in place. 
As mentioned, Cirkus gains the quality of tellability at the discourse level. It is not in any obvious way inherent in what is told. Rather, what makes it a good illness narrative is the experimentation with the affordances of the multimodality of comics, which I will address in the next section.

\section{Why Comics? Reflection, Time, Silence}

Comics artists have been composing autobiographies in comics since the 1970'ies. Graphic memoir seems to be the accepted label for this genre but, as Nancy Pedri notes, a number of alternative names have been proposed such as autographics, comic book memoir, autography, autographic memoir, graphic novel memoir, and autobiocomics (Pedri, 2013: 127). Since the turn of the millennium, graphic memoirs about illnesses have proliferated, and graphic medicine is a well-established academic research area within health humanities. What makes comics so well suited to represent the experience of illness autobiographically? I want to suggest at least three reasons, and in elaborating on the rationale behind them, I will continue the theoretical discussion in the previous section by testing the theory in an interpretation of Nøhr's Cirkus: 1.) its verbal-visual multimodality allows for play with the narratological distinction between the narrating I and the experiencing I, which relates to the question of whether one has mastery over one's story, 2.) the potential to experiment with narratological concepts of time, and 3.) the visual track can represent that, which cannot be put into words.

Narratology distinguishes between the narrating I and the experiencing I. The underlying premise is that first-person narrators are like people in real life. They can only report on something after it has taken place - not before or during the event. This means that the narrating I in literature (at least in theory) reports at a temporal distance from what was experienced. According to Dorrit Cohn, the relation between the narrating I and the experiencing I can be either dissonant or consonant. In dissonant narration, the narrator "remains emphatically distanced from the consciousness he narrates," while consonant narration "is mediated by a narrator who remains effaced" (Cohn, 1983: 26). Graphic memoirs conventionally represent the narrating I as text in the captions. The experiencing I, then, inhabits the visual track as an avatar, i.e. a comics-style version of the autobiographical author. The discourse of the avatar/the experiencing I is represented as direct speech in speech bubbles or thought quotations in thought bubbles. The split between the narrating and experiencing I, hence, is foregrounded in graphic memoirs, which makes it 
primed for dissonant narration. Cohn writes that in dissonant self-narration, " $[t] h e$ narrative process itself [...] is emphatically conscious, deliberate, and intellectual" (Cohn, 1983: 146). This would fit well with graphic memoirs about illness that function as restitution or quest narratives, but it goes counter to key features of the chaos narrative:

"When I refer below to the chaos narrative, I mean an anti-narrative of time without sequence, telling without mediation, and speaking about oneself without being fully able to reflect on oneself." (Frank, 1995, 98)

Nøhr's Cirkus does not employ dissonant narration. It is a curious case: on the one hand, it represents the overwhelming chaos imposed on Nøhr in his meeting with the health care system, and Nøhr mentions that he created it while engulfed in the chaos of the process; on the other hand, everything is meticulously arranged by Nøhr, so he has clearly been able to work artistically on giving form to the experience. Cirkus mimicks time without sequence, telling without mediation, and speaking about oneself without reflective distance, but clearly, there is mediation, and as mentioned the experience's tellability is recuperated at the discourse level. Nøhr mimics the lack of reflexive distance by employing consonant self-narration rather than dissonant self-narration. This might be termed the mediated chaos narrative. Nøhr does this in a visually conspicuous way by simply deleting - or, rather, leaving empty - all captions (save for a few time markers), i.e. the exact spot which the narrating I would otherwise inhabit. The potential to play with the narratological split between the narrating I and the experiencing I is one of the reasons why the graphic memoir is well suited to depict illnesses, as Jared Gardner has also commented on: "Comics autobiography from Green to Bechdel highlights that split and puts it to productive use, allowing the autographer to be both victim of the trauma and detached observer" (Gardner, 2008: 12). Nøhr's Cirkus is a chaos narrative that stresses the what it's like or experientiality of Nøhr's traumatizing ordeal and quest to get help. The position of the narrating I is deleted, but ambiguously some detached observer position is nonetheless indicated by the fact that the avatar is seen from the outside or drawn in the third person (like a character in a movie) and by Nøhr's overall construction of the discourse level.

Another reason why tellability is recuperated at the discourse level is Nøhr's experimentation with the comics medium's potential for time representation. Time is an important aspect of plot, and I have argued that the chaos narrative in general and Nøhr's Cirkus, in particular, lose the plot (if you will forgive the 
pun). So how and to what ends does Nøhr play with time categories? In Narrative Discourse, a seminal essay by the structuralist narratologist Gérard Genette, time is divided into three subcategories: order, duration, and frequency. The temporal order refers to the comparison between the order of the events at the story level with the order at the discourse level. The discourse's order is characterized by chronology or anachrony (the latter comes in many shapes). As mentioned, Cir$k u s$ is straightforwardly chronological, which contributed to the syntactic effect of 'and then and then and then'.

Frequency is more complex in Cirkus. Time-frequency is singulative when you narrate once what happened once. You can also narrate many times what happened only once. Finally, you can narrate one time what happened more than once (e.g.: Every day for 5 years I went to bed at 10). Genette calls the latter form for the iterative. Nøhr's avatar in Cirkus goes through the same motions so many times, and what he and the other characters say in dialogue is almost identical each time, so at a first glance, you might think that he is narrating many times what happened once. However, it is, in fact, singulative: "the repetitions of the narrative simply correspond [...] to the repetitions of the story" (Genette, 1972: 115). This is, in fact, Nøhr's point: he should only need to get the statements once, but the system forces him to do essentially the same thing several times, rendering the singulative frequency circular. While the same thing happens over and over, the graphic world is gradually distorted, transforming into a surreal or nightmarish universe, before eventually being substituted for innumerable, non-figurative coloured panels. This immediately becomes obvious, when one compares figures 1-3. In figure 2 , for instance, the secretary at the front office continues to speak to him in a friendly and accommodating way but visually the reader only sees a fragment of her face and she looks more and more daemonic (with sharp teeth and all). The fact that the panels become smaller as they grow in number accelerates the singulative (yet somehow repetitive) aspect of frequency. The panels gradually become less anthropomorphic (with fewer human-like figures and less speech) and, finally, they turn into non-figurative colours. At this point the materiality of the comics medium becomes visible. The shapes and colours in figure 3 are overdetermined. The panels and frames resemble both grids, prison bars, fences etc. As Nøhr's avatar disappears (his final word being the single-syllable word: "Help"), it is suggested that he has been chewed up by the system.

The accelerated frequency has an implication for the final time category. Duration addresses the narrative time (NT) compared to the story time (ST). ST refers to the time an event actually takes, whereas NT designates the time it (roughly) 
takes to narrate that same event. The narrative time is most often shorter than the story time. NT can to some degree be measured by the amount of text space an event takes up. Genette then distinguishes between the pause (e.g. a description where NT is infinitely greater than ST), the scene (e.g. a dialogue where NT is the same as ST), the summary (where NT is shorter than ST; the correspondence between the two in this category can vary greatly) and, finally, the ellipsis (where NT is infinitely shorter than ST). We do not get pauses in Cirkus. Even as a panel is a frozen moment time in comics is spatial. Some time will have gone as readers move from one panel to the next. In figure 1, it is even made explicit that one month goes by between some of the panels. What is interesting, is the fact that even though the story time ellipsis, which inhabits the blank space between two panels, is of one month, the avatar does not really change (he sinks a little and the colours darken). This sequence is strange, indeed. Cirkus is autobiographical (i.e. technically speaking it should be read as nonfiction) at a global or generic level. However, Nøhr reverts to fictive discourse on numerous occasions at a local level (cf. Nielsen, Phelan, \& Walsh, 2015, p. 62 for a theoretical distinction between local and global fictionality). In the passage just mentioned, the secretary asked him to take a seat in the waiting room: Clearly, we are not invited to imagine that he literally spends +4 months sitting in a chair in a waiting room, even though this is what the visual side indicates. Nøhr also fictionalizes time categories, when the plot repeats itself in figures 2 and 3. The NT shortens in its depiction of the very same ST. This increases the number of panels and accelerates time-frequency. The panels become smaller and smaller just as they grow in numbers, which helps accelerate the speed of the repeated events. Cirkus, thus, represents a kind of spiralling downwards, a catabasis down to the hell that is the health care system, if you will. This is another blatant example of Nøhr's foray into fictive discourse at a local level: it is hyperbolic to suggest that he had to procure the statements from the doctor and the psychiatrist an infinite number of times. Nøhr exaggerates the singulative frequency to say something about the absurdity of the situation and to demonstrate the effect the circular, repetitive process has on him.

\section{Conclusion}

Counter-discourses directed at a society's psychiatric system - as one encounters in, e.g., literature with anti-psychiatry sentiments - has traditionally been centred on coercion in psychiatry (e.g., forced biomedical treatment, electro-convulsive 
therapy or compulsory admission to a mental institution). Nøhr, however criticizes the Danish welfare system's way of distributing help. In district psychiatry, treatment takes place on an outpatient basis, and help is distributed with reference to a generalized system of classification and diagnoses with set symptoms clusters. In order to receive help - in Nøhr's case, he needs to be exempted from job market availability - you first need to receive a diagnosis to prove that you are ill and, hence, in need of help. The quest to get help, thus, becomes a quest to receive a formal diagnosis that will elicit the help. It results in a system that is deemed highly bureaucratic and inefficient by Nøhr. The criticism is inherent in the very title, Cirkus. Of course, it refers to the repetitive circularity, but it also suggests that the patient is made to feel like a circus animal that is trained to perform tricks for treats. Nøhr, of course, presents the evidence of the plaintiff, so to speak. The Department of Health might make the counter-argument that placing people on disability pension is detrimental to the nation's financial situation and should, therefore, not be distributed lightly.

Revisiting Arthur Frank's notion of a chaos narrative, I have suggested that it is fruitful to supplement the chaos narrative by the concept of tellability. Furthermore, I have claimed, that Frank's argument; that the chaos narrative is really an antinarrative, entails an implicit definition of narrative that is too reliant on plot. Put differently, the chaos narrative does not have to be defined as an anti-narrative, if plot is not viewed as indispensable to a definition of what constitutes a narrative. Experientiality or what it's are apt terms to account for narrativity in the chaos narrative. If a prototypical approach to definitions of narrative is employed, the chaos narrative is a narrative, just not a prototypical narrative. Experientiality or what it's like are foregrounded at the expense of plot.

In The Wounded Storyteller, Frank presents the chaos narrative as one that is predominantly communicated verbally, one that cannot be represented. I have suggested, that we modify this position by introducing what might be termed the mediated chaos narrative, in which the chaos is mimicked even as the representation is highly artificial and meticulously orchestrated. In the mediated chaos narrative, the ill protagonists are not just lost in the chaos. They can also exhibit irony and satire. To scrutinize the mediated chaos narrative in the interpretation of Nøhr, I supplemented the theory of the chaos narrative and of experientiality and what it's like with narratological distinctions between story and discourse, the narrating I and the experiencing I, and the time categories order, duration and frequency. Once the plot recedes into the background, the play with narrative and fictive discourse is foregrounded. 
Finally, I have argued that the affordances of the graphic memoir makes it well suited to represent the mediated chaos narrative. The feedback loop between the theory and the empirical material led to critical arguments with theoretical implications. Even as I rely on small sample size - Cirkus, a single graphic memoir - I argue, that Nøhr employs the graphic memoir's affordances to experiment with narrative building blocks like narrative situations and time categories. Hence, the feedback loop between Nøhr's experimental graphic memoir and the theory applied in my interpretation thereof was crucial to the theoretical implications that it led to. Additional graphic memoirs - one example might be Art Spiegelman's In the Shadow of No Towers - might corroborate the findings, but it should also be emphasized that there are graphic memoirs about illness that qualify as restitution and quest narratives.

\section{Notes}

1 I would like to thank Felix Kühn Paulsen for introducing me to Nøhr's work and for inviting me to speak at a seminar at Aarhus University, where the ideas for this article were first presented.

2 Circus is in Danish. All translated quotations from Danish to English in this article are ad hoc translations by Lasse R. Gammelgaard.

\section{References}

Andreasen, S. (2017). Han tegner følelsen af stress og depression. Seneste Nyt Kalundborg. URL: https://sn.dk/Kalundborg/Han-tegner-foelelsen-af-stress-og-depression/artikel /643818?fbclid=IwAR0jefoKsyBJNDHXLhhhcR0eBsDmGL2-9aW85pgEdk1_TlyTeCVstuM9w2E. Viewed October 262018.

Aristotle (1981). Poetics. Tallahassee: Florida State University Press.

Baroni, R. (2011). Tellability. In P. Hühn et al. (Eds.), The Living Handbook of Narratology. Hamburg: Hamburg University. URL: http://www.lhn.uni-hamburg.de/article/tellability. Viewed October 262018.

Cohn, D. (1983). Transparent Minds: Narrative Modes for Presenting Consiciousness in Fiction. Princeton: Princeton University Press.

Fludernik, M. (1996). Towards a 'Natural' Narratology. New York, USA: Routledge. https://doi. org/10.4324/9780203432501

Frank, A. (1995). The Wounded Storyteller: Body, Illness, and Ethics. Chicago, USA: The University of Chicago Press. https://doi.org/10.7208/chicago/9780226260037.001.0001

Gardner, J. (20018). Autography's Biography, 1972-2008. Biography, 31.1, 1-26. https://doi. $\operatorname{org} / 10.1353 /$ bio.0.0003 
Genette, G. (1980 [1972]). Narrative Discourse: An Essay in Method. (J. E. Lewing, Trans.). New York, USA: Cornell University Press.

Herman, D. (2009). Basic Elements of Narrative. Malden, USA: Wiley-Blackwell. https://doi. org/10.1002/9781444305920

Larsen, K. B. (15-04-2015). "Som en pludselig kvalme der ikke lader sig holde tilbage«. Nummer 9: Magasinet om tegneserier. URL: http://nummer9.dk/artikler/som-en-pludseligkvalme-der-ikke-lader-sig-holde-tilbage/. Viewed October 262018.

Nielsen, H. S., J. Phelan, \& R. Walsh (2015). Ten Theses about Fictionality. Narrative, 23.1: 61-73. https://doi.org/10.1353/nar.2015.0005

Nøhr, T. H. (2017). Når jeg tegner... Aarhus: Forlaget desAHJn.

Pedri, N. (2013). Graphic Memoir: Neither Fact Nor Fiction. In D. Stein \& J.-N. Thon (eds.), From Comic Strips to Graphic Novels: Contributions to the Theory and History of Graphic Narrative (pp. 126-153). Boston: De Gruyter.

Rimmon-Kenan, S. (2006). What Can Narrative Theory Learn from Illness Narratives? Literature and Medicine, 25.2, 241-254. https://doi.org/10.1353/1m.2007.0019

Ryan, M.-L. (2005). Tellability. In D. Herman, M. Jahn, \& M.-L. Ryan (Eds.), Routledge Encyclopedia of Narrative Theory (pp. 589-591). New York: Routledge. 